Arts

\title{
DIGITAL TECHNIQUES AND ART
}

\author{
Dr Avinash Dube *1 \\ ${ }^{* 1}$ Professor, (Physics), S.N. Govt. P. G. College, Khandwa
}

\begin{abstract}
Modern age is a digital age. Digitalization is improving the things in all sectors. In electronics digital instruments are replacing conventional analog instruments giving precession and accuracy. Teaching learning methods are greatly improved due to incorporation of digital technology. Life style of common people is also changing due to digital tranjections, online shopping, online banking etc. The field of art and painting is also influenced by digital techniques available now a day.

With emergence of new tools and techniques the art of painting is gaining new shapes. Digital technical skills provide a wide platform for imagination of artists. There are pros and cons of each aspects but it is true that art always connect students with their own culture as well as with the wider world. Visual art always improve learners critical thinking.
\end{abstract}

Keywords: Digital Age; Digital Painting.

Cite This Article: Dr Avinash Dube. (2019). "DIGITAL TECHNIQUES AND ART ." International Journal of Research - Granthaalayah, 7(11SE), 89-91. 10.29121/granthaalayah.v7.i11.2019.3706.

\section{Introduction}

Art is an expression of a sentient being through or an accessible medium so that anyone can view, hear or experience it. The arts as painting, sculpture, music, theater considered as activities done by people with skill and imagination. Painting is a mode creative expression and can be done in numerous forms. It is an important form of visual art, which describes both the act and the result of action. Its main object is to making an image using any of the wide variety of tools and techniques. With emergence of new technology the art of painting is also gaining new shapes. Digital painting is one of the results of modern techniques which include a method of creating an art object digitally.

The present study is made to analyze the tools and techniques, advantages of digital paintings because it is not only a computer generated art but a combination of artists imagination and technical skills. 


\section{Techniques and Tools in Digital Paintings}

Digital technology and modern techniques have had the strongest impact on the art of painting and drawing .The artist through conventional and calculated steps was in control of the density of colour, the degrees of different shades, the realism or abstraction of his work of art. Artists today operate with clicks of mouse, video tools and digital colors. Digital painting is an emerging art form, in which traditional painting techniques as water color, oil, etc. are applied using digital tools by means of computer, a graphic tablet, stylus and software. Digital painting is a technique which refers to a computer graphics software program, that uses a virtual canvas and virtual painting box of brushes, colors and other supplies. But it is not only a computer generated art as the computer does not automatically create images on the screen using some mathematically calculations.

All digital painting programs try to mimic the use of physical media. There are also certain effects unique to each type of digital paint. These software give artists a similar environment to a physical painter. Origins, sketchpad, tablets, macpaints, adobe photoshop, kid pix are paint programmes. In recent years there are websites which support painting digitally online. The user is still drawing digitally with the use of software often the software is on the server of the website which is being used.

Apart from the traditional tools, the virtual painting box contains instruments that do not exist outside the computer. They bear some resemblance to paper cutouts or stencil art with specific traits which include transparency, symmetry, sharp and bold appearance, exact repetition, perfect shapes, embossing, shading and other $3 \mathrm{D}$ illusion, $100 \%$ monochrome color planes and effects of automatic transformation in the form of mirror, ripples, swirls, shear, multiply etc.

Based on the different methods and appearance five mainstream directions can be recognized-

1) Computer generated painting.

2) Raster painting

3) Manual vector painting

4) Mixed media and hybrid painting

5) Digital photo art

\section{Advantages and Disadvantages}

Technique of digital painting is more efficient. It is easy to get started and work quickly. It is more forgiving because nothing is permanent. It has unlimited experimental possibilities and it is ideal for working.

Today much more equipment's and materials are available. But simultaneously digital painting art is only for pros or advanced level. A high quality drawing appliances and money is involved in this. Glitches, freezes or slow internet connection may produce some troubles during performance. A lot of practice is also required for this work. 


\section{Importance in Education}

Visual art teach learners about color, layout, perspective and balance, these all techniques are necessary in presentation of academic work improving the teaching learning process. Working in the art like painting or drawing helps learners to develop creative problem solving skills. Art instruction helps to students with the development of motor skills, language skills, social skills, decision making, risk taking and inventiveness.

Integrating art with other disciplines reaches students who might not otherwise be engaged in classwork. It also helps to boost critical thinking. It is also noted that early childhood art education improve vocabulary, communication and memory in young children. The arts provide students with a multitude of options for expressing and communicating their ideas and student learn to think about problems from a broad range of perspectives.

\section{Conclusion}

Modern age is a digital age. Digitalization is improving the things in all sectors. In electronics digital instruments are replacing conventional analog instruments giving precession and accuracy. Teaching learning methods are greatly improved due to incorporation of digital technology. Life style of common people is also changing due to digital tranjections, online shopping, online banking etc. The field of art and painting is also influenced by digital techniques available now a day.

Art and techniques have become more intertwined than even before. Whether its through providing new ways to mix different types of media, allowing more human interaction simply making the process of creating it easier. Painting is all about creativity so artists do not restrict themselves to only limited medium and materials. Digital painting is a method of creating an art object digitally by using various techniques. It is more efficient, ideal and provides much more possibilities for creation. But it needs a high quality tools, money, skills and practice. As an innovative part of painting art digital painting provides a wide area of imagination, which develops creative problem solving skills in human beings.

\section{References}

[1] Digital portrte painting (2016), www.research gate.net.

[2] Digital painting techniques (2009), books.google.co.in. 